\title{
Emprego de inserts em silos metálicos: revisão sobre o padrão de fluxo dos produtos e distribuição das cargas na estrutura
}

\author{
Use of inserts in metal silos: review of the flow pattern of products and distribution of loads in the
} structure

Uso de insertos en silos metálicos: revisión del patrón de flujo de producto y distribución de carga en la estrutura

\section{Resumo}

Os silos verticais são estruturas utilizadas pelas indústrias, setor agrícola e mineral para armazenar e conservar a granel, produtos sólidos granulares ou pulverulentos. Contudo, silos são estruturas que podem apresentar grande número de falhas estruturais e de fluxo, especialmente pela diversidade de variáveis que afetam o comportamento estrutural e a ausência de normas nacionais específicas para o cálculo de ações em silos. Na busca por novas alternativas que favoreçam a produção e reduzam custos sem afetar a qualidade do produto final, destaca-se o uso de inserts por reduzir problemas como descarregamento desuniforme, segregações, obstruções parciais ou totais no fluxo, reduzindo desta maneira possíveis prejuízos produtivos a indústria e problemas na integridade física do silo. Entretanto, a simples adoção de inserts em silos verticais sem um conhecimento prévio de algumas características como forma e dimensões mais apropriadas para cada situação pode não obter o resultado desejado além do fato de gerar problemas no fluxo dos produtos. Diante desta insegurança, a presente revisão teve como objetivo realizar uma abordagem sobre o comportamento de fluxo dos produtos armazenados e das pressões que ocorrem com a presença de inserções no interior da estrutura, apresentando resultados do emprego desses dispositivos em silos verticais, possibilitando a elaboração de projetos seguros, robustos e confiáveis.

Palavras-chave: Fluxo de massa; Fluxo de funil; Obstrução de fluxo; Pressão; Processamento de partículas.

\begin{abstract}
Vertical silos are structures used by industries, the agricultural and mineral sectors to store and conserve bulk, granular or powdery solid products. However, silos are structures that can present a large number of structural and flow failures, especially due to the diversity of variables that affect structural behavior and the absence of specific national norms for calculating actions in silos. In the search for new alternatives that favor production and reduce costs without affecting the quality of the final product, the use of inserts stands out for reducing problems such as uneven discharge, segregation, partial or total obstructions in the flow, thus reducing possible productive losses to industry and problems with the physical integrity of the silo. However, the simple adoption of inserts in vertical silos without prior knowledge of some characteristics such as the most appropriate shape and dimensions for each situation may not achieve the desired result besides the fact that it generates problems in the flow of products. In view of this insecurity, the present review aimed to approach the flow behavior of stored products and the pressures that occur with the presence of insertions inside the structure, presenting results of the use of these devices in vertical silos, enabling the elaboration of safe, robust and reliable designs.
\end{abstract}

Keywords: Mass flow; Funnel flow; Flow obstruction; Pressure; Particle processing.

\section{Resumen}

Los silos verticales son estructuras utilizadas por las industrias, los sectores agrícola y minero para almacenar y conservar productos sólidos a granel, granulados o en polvo. Sin embargo, los silos son estructuras que pueden 
presentar una gran cantidad de fallas estructurales y de flujo, especialmente por la diversidad de variables que afectan el comportamiento estructural y la ausencia de normas nacionales específicas para el cálculo de acciones en silos. En la búsqueda de nuevas alternativas que favorezcan la producción y reduzcan costos sin afectar la calidad del producto final, se destaca el uso de insertos por reducir problemas como vertidos irregulares, segregaciones, obstrucciones parciales o totales en el flujo, reduciendo así posibles pérdidas productivas. a la industria y problemas en la integridad física del silo. Sin embargo, la simple adopción de insertos en silos verticales sin el conocimiento previo de algunas características como la forma y dimensiones más adecuadas para cada situación puede no lograr el resultado deseado además de generar problemas en el flujo de productos. Ante esta inseguridad, la presente revisión tuvo como objetivo abordar el comportamiento de flujo de los productos almacenados y las presiones que se producen con la presencia de inserciones dentro de la estructura, presentando resultados del uso de estos dispositivos en silos verticales, posibilitando la elaboración de cajas diseños robustos y fiables.

Palabras clave: Flujo de masa; Flujo de embudo; Obstrucción del flujo; Presión; Procesamiento de partículas.

\section{Introdução}

$\mathrm{O}$ crescimento da produção agrícola nas últimas décadas resultou em aumento da demanda por instalações de armazenamento pelo mundo. No Brasil, de acordo com a Companhia Nacional de Abastecimento, estima-se para safra 2020/21 um total de 268,7 milhões de toneladas, 11 milhões de toneladas superior ao colhido em 2019/20, com destaque para as commodities de soja e milho (Conab, 2021). Contudo, o ritmo intensificado da produção não foi acompanhado na mesma proporção pela capacidade estática de armazenagem do país, apresentando um déficit de cerca de 80 milhões de toneladas. Desta forma, a construção de silos verticais surge como uma alternativa para solução deste problema.

Os silos verticais são estruturas comumente utilizadas pelas indústrias, setor agrícola e mineral para armazenar e conservar a granel, produtos sólidos granulares ou pulverulentos. Ao projetar silo, o objetivo principal é garantir a qualidade do produto e pelo lado funcional de operação que os sólidos armazenados fluam sob a ação da gravidade, sem obstruções do fluxo. Entretanto, grande número dos silos existentes não apresenta condições ideais de operação devido ao insuficiente conhecimento das pressões que variam no tempo e no espaço interno, do fluxo e das variáveis que afetam o comportamento dos produtos armazenados (Tascón, 2017; Ayres et al., 2020). Tal situação tem contribuído para os acidentes e colapsos em silos.

Os tipos de padrões de fluxo produzidos no interior dos silos têm um efeito significativo na distribuição da pressão dinâmica exercida nas paredes e tremonha (Hammadeh et al., 2019; Saleh et al., 2018; Xue et al., 2019). Podem-se formar basicamente dois tipos de fluxo durante a descarga, o de massa e funil. O primeiro caracteriza-se pelo movimento de todas as partículas no interior da estrutura, imediatamente após abertura do orifício de descarga. Em contrapartida, o segundo é definido pela formação de um canal preferencial de fluxo e porções de produtos estagnadas no entorno das paredes (Fullard et al., 2020).

Os inserts surgem como opção para solução de problemas de fluxo, redução das pressões na estrutura durante a descarga ou indução do padrão de fluxo necessário, por agir alterando os estados de tensão principalmente na zona de transição da tremonha, além de promover a redistribuição das partículas antes de atingirem o orifício de descarga (Zuriguel et al., 2011; López et al., 2014; Ding et al., 2015; Kobyłka et al., 2019). Uma grande variedade de configurações de inserts é empregada, por exemplo, formas básicas, como cones, discos ou anéis, e mais elaboradas, como cone duplo e BINSERT® (Yang \& Hsiau, 2001; Hartl et al., 2008; Wójcik \& Tejchman, 2008; Wójcik et al., 2012; Kobyłka et al., 2019).

O emprego dos inserts constituem alternativas interessantes para silos quando há espaço livre limitado ou quando há necessidade de uma modificação para solucionar um problema de fluxo em um silo existente (Bandeira et al., 2020). O custo de instalação de um insert é muito menor do que o custo da reforma ou modernização de equipamento para melhorar o fluxo.

Apesar de muitas pesquisas, ainda não há recomendações detalhadas em normas de como calcular as cargas nos inserts e sua influência na distribuição de pressão dentro do leito granular ou no padrão de fluxo (Hammadeh et al., 2019; Kobyłka et al., 2020). Outro fator a ser considerado é a localização adequada do insert, desempenhando um papel crucial na 
obtenção da correção desejada do padrão de fluxo. As inserções em silos são geralmente colocadas dentro da tremonha (Hartl et al., 2008), o posicionamento muito baixo ou acima da zona de transição entre a parede e tremonha pode aumentar o arqueamento, diminuir a taxa de descarga, bloquear o fluxo do produto (Hsiau et al., 2013; Hammadeh et al., 2019; Kobyłka et al., 2019) ou até comprometer a estrutura com distribuição desigual das pressões que geram cargas assimétricas no descarregamento (Kobyłka et al., 2020).

Diante do exposto, observa-se que para garantir a competitividade do país em um mundo globalizado, a construção de silos é uma premissa necessária tanto para produtores agrícolas quanto indústrias, sendo aqui inserida uma abordagem de forma sistêmica a influência de inserts sobre o padrão de fluxo do produto e distribuição das cargas na estrutura. A ausência de códigos normativos que orientem o emprego desses dispositivos justifica a importância de estudos que contribuam para projetos de silos verticais com inserções, possibilitando a elaboração de projetos seguros, robustos e confiáveis.

\section{Metodologia}

Esta revisão de literatura constitui um estudo de caso de caráter exploratório e informativo (Pereira et al., 2018) apresentando uma explanação de forma abrangente o comportamento de fluxo dos produtos armazenados e das pressões que ocorrem com a presença de inserções no interior de silos, apresentando-se como um estudo que contribuirá para projetos de silos com esses dispositivos. Realizou-se uma busca de trabalhos correlatos ao assunto proposto, selecionando-se de forma criteriosa artigos e trabalhos científicos de impacto que abordam a referente temática, caracterizando-se como uma pesquisa de natureza qualitativa (Pereira et al., 2018).

Parte-se de um percurso pela literatura referente a uma perspectiva histórica da caracterização e importância dos silos, contribuição sobre o fluxo dos produtos armazenados em silos, sobre os modelos de inserts, contribuição sobre o emprego desses dispositivos como parte influente para o estudo do escoamento do produto ensilado e pressões na estrutura. Os artigos selecionados para elaboração do presente trabalho foram retirados dos respectivos bancos de dados: Elsevier, Google Acadêmico, Periódicos Capes, Pubmed, Scielo, Scopus e Science Direct, na qual foram elaboradas sínteses de conhecimento prioritário entre os artigos da decante corrente (2011-2021), sem desconsiderar os trabalhos relevantes de anos anteriores.

\section{Resultados e Discussão}

\subsection{Silos: caraterização e importância}

Silos são células individualizadas, construídas em chapas metálicas, alvenaria ou concreto, possuindo ou não sistema de aeração e, propiciando condições para preservação da qualidade do produto e, os primeiros silos altos (esbeltez elevada) foram construídos no final do século XIX para armazenamento de grãos (Gallego et al., 2015). Os silos são estruturas de armazenamento amplamente utilizadas pelo setor agrícola e industrial, como mineração, química e alimentícia, para materiais granulares e pulverulentos (Yu et al., 2017; Zhang et al., 2018), sendo equipados com dispositivos de carregamento e capazes de serem esvaziadas, preferencialmente, pela ação da gravidade ou com auxílio de dispositivos mecânicos ou pneumáticos.

Para a norma europeia (European Committee of Standardization - EN 1991- 4:2006), silos são definidos como estruturas utilizadas para o armazenamento e a conservação de produtos sólidos particulados, a granel ou pulverulentos, enquanto a norma internacional ISO 11697:2012, emprega o termo silo para representar todas as formas de armazenamento.

Esse tipo específico de construção apresenta expressiva importância para o Brasil pelo boom do setor agropecuário (Rodrigues et al., 2018), onde o país consolidou-se no cenário mundial como um dos maiores produtores e exportadores de commodities agrícolas e proteína animal e, em termos de exportação, destacam-se a soja, milho, frango, carne bovina, suína e farelo de soja (Ibge, 2020).

No ranking mundial de exportações de proteína animal, o país ocupa o primeiro lugar para carne bovina e aves e, para 
manutenção da competitividade econômica do país em relação a produção e exportações de carnes, é necessário domínio sobre a tecnologia de construção de silos, muitos deles utilizados em fábricas de rações (Lopes Neto et al., 2008).

A capacidade estática de armazenagem é importante para a comercialização de produtos agrícolas, onde os produtores podem negociar os produtos por preços mais atrativos na entressafra, evitam gargalos logísticos e a agroindústria garante a qualidade e a continuidade no fornecimento das matérias-primas utilizadas no processo produtivo (Silva Neto \& Santos, 2019).

Contudo, a evolução da capacidade estática brasileira não ocorreu na mesma proporção que produção agropecuária. A capacidade estática total registrada no Brasil em 2019 foi de 169,8 milhões de toneladas, culminando um déficit de aproximadamente 80 milhões de toneladas (Conab, 2020) e, o fato de o país tornar-se grande produtor de grãos e seus derivados, salienta as preocupações quanto ao armazenamento, onde além da excelência em termos de produção, se faz necessário investimento em silos (Baroni et al., 2017).

\subsection{Fluxo em silos}

Contudo, a evolução da capacidade estática brasileira não ocorreu na mesma proporção que produção agropecuária. A capacidade estática total registrada no Brasil em 2019 foi de 169,8 milhões de toneladas, culminando um déficit de aproximadamente 80 milhões de toneladas (Conab, 2020) e, o fato de o país tornar-se grande produtor de grãos e seus derivados, salienta as preocupações quanto ao armazenamento, onde além da excelência em termos de produção, se faz necessário investimento em silos (Baroni et al., 2017).

A descarga de produtos pulverulentos e granulares por gravidade tem sido um assunto de interesse para as comunidades acadêmicas e industriais (Saleh et al., 2018; Hammadeh et al., 2019; Xue et al., 2019). Se esse assunto intrigou muitos cientistas desde a antiguidade, assumiu uma nova dimensão desde a era industrial, quando quantidades crescentes de materiais passaram a ser armazenados como produtos finais ou como matérias-primas em processos produtivos (por exemplo, carvão, minério de ferro, açúcar, grãos e cereais, cimento, etc.). De fato, é difícil encontrar um produto granular que não tenha estado, em um momento ou outro de seu ciclo de vida, em um silo (Saleh et al., 2018).

A fluidez de um material é uma característica complexa, dependente não apenas das propriedades do produto, mas também do histórico de tensões submetidas ao material e fatores estruturais (rugosidade da parede, ângulo da tremonha etc.) (Koynov et al., 2015; Mathews \& Wu, 2016). Os tipos de padrões de fluxo produzidos no interior dos silos têm um efeito significativo na distribuição da pressão dinâmica exercida nas paredes e tremonha (Hammadeh et al., 2019; Saleh et al., 2018; Xue et al., 2019).

O tipo de fluxo caracteriza o descarregamento do produto, a formação ou não de zonas estagnadas de produto, se o silo pode ser esvaziado totalmente, o tipo de segregação do material, além de determinar a integridade e custo da construção, pelo fato de influenciar na distribuição das pressões nas paredes do silo e fundação (Calil Júnior, 1990).

Podem-se formar basicamente dois tipos de fluxo durante a descarga, o de massa e funil (Figura 1). O primeiro caracteriza-se pelo movimento de todas as partículas no interior da estrutura, imediatamente após abertura do orifício de descarga (Oginni \& Fasina, 2018). Em contrapartida, o segundo é definido pela formação de um canal preferencial de fluxo e porções de produtos estagnadas no entorno das paredes (Fullard et al., 2020). O fluxo de massa ocorre normalmente quando as paredes da tremonha são suficientemente inclinadas e lisas (baixo coeficiente de atrito) e não existem abruptas transições e o fluxo do funil é padrão típico para silos de fundo plano (Olivares et al., 2018).

Além destes, há um terceiro tipo de fluxo, caracterizado por um regime de transição entre os outros dois, ou seja, uma combinação de fluxo de funil para partículas próximas ao orifício de descarga até uma determinada altura e um fluxo de massa para partículas do topo até um determinado ponto do corpo do silo (Figura 1). Denominado de fluxo misto, é característico para tremonhas com pequenas inclinações das paredes (Olivares et al., 2018) sendo característico de silos esbeltos, cuja relação 
H/D $\geq 2$ (Sadowski \& Rotter, 2011).

Figura 1. Tipos de fluxo em silos com descarga concêntrica.

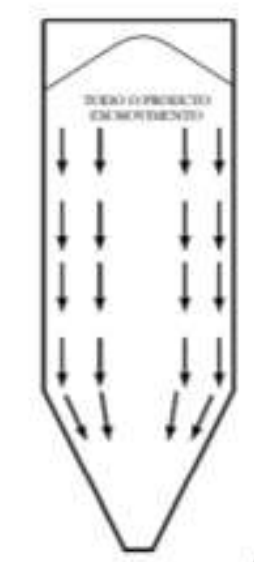

FUXO DE MASSA

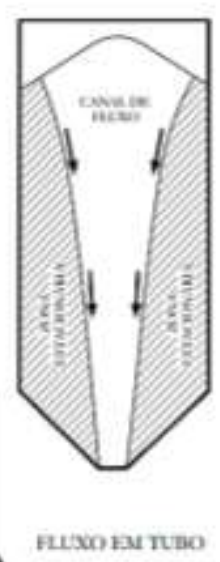

FUXO DE FUNIL

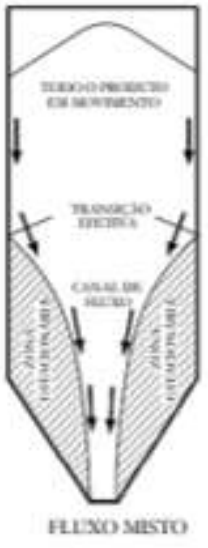

Fonte: EN 1991-4 (2006).

A diferença básica entre o fluxo de funil e o misto reside no fato de que no fluxo do funil as partículas que fluem não entram em contato com as paredes do silo, enquanto no fluxo misto, o limite do fluxo cruza a parede do silo em algum ponto (Wang et al., 2015). As possíveis configurações do canal de fluxo no interior dos silos em função de sua esbeltez são apresentadas na Figura 2.

Figura 2. Efeitos da esbeltez no fluxo.

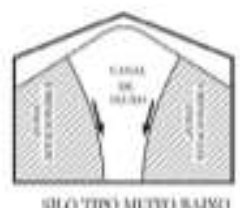

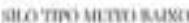

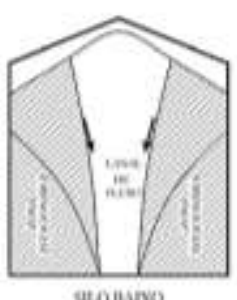

stomines

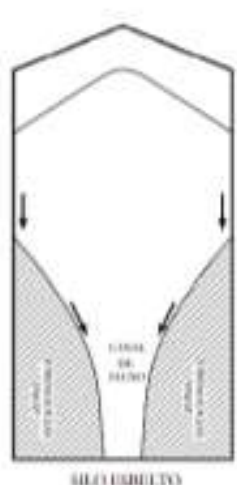

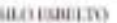

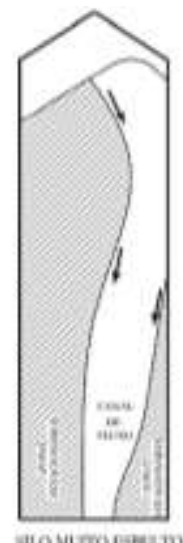

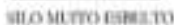

Fonte: EN 1991-4 (2006).

As principais normas estrangeiras para cálculo de pressões em silos: International Organization for Standardization ES ISO 11698:2012, europeia (European Committee of Standardization - EN 1991-4:2006) e australiana (Australian Standard AS 3774:1996), apresentam procedimentos para determinação do tipo de fluxo, conforme apresentado nas Figuras 3, 4, 5 e 6, respectivamente.

Os gráficos apresentados nas normas supracitadas predizem o tipo de fluxo em função de alguns parâmetros, sendo eles: ângulo ou coeficiente de atrito do produto com a parede, inclinação das paredes da tremonha e de sua geometria (comumente cônicas ou piramidais e as concêntricas). 
Research, Society and Development, v. 10, n. 4, e55710414580, 2021

(CC BY 4.0) | ISSN 2525-3409 | DOI: http://dx.doi.org/10.33448/rsd-v10i4.14580

Figura 3. Determinação do tipo de fluxo pela ES ISO 11697 (2012) para tremonha cônica.

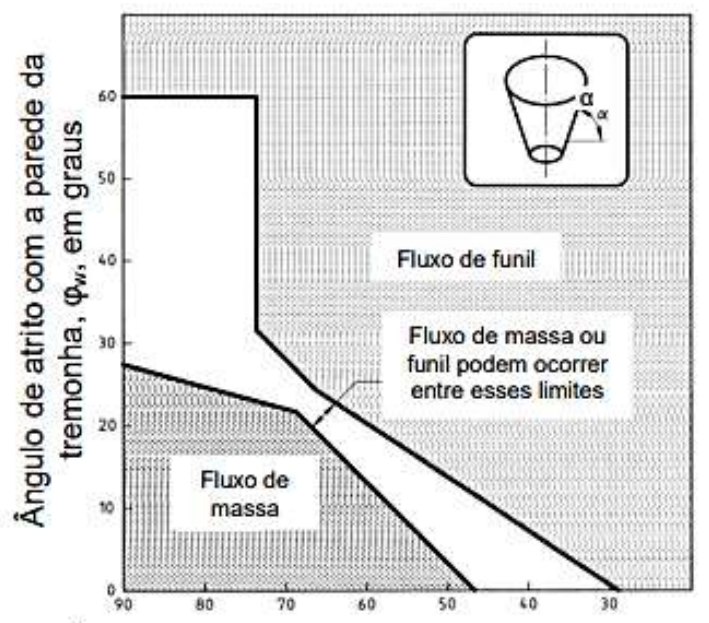

Ângulo de inclinação da tremonha, $\alpha$, em graus

Fonte: Paula (2020).

Figura 4. Determinação do tipo de fluxo pela ES ISO 11697 (2012) para tremonha em cunha.

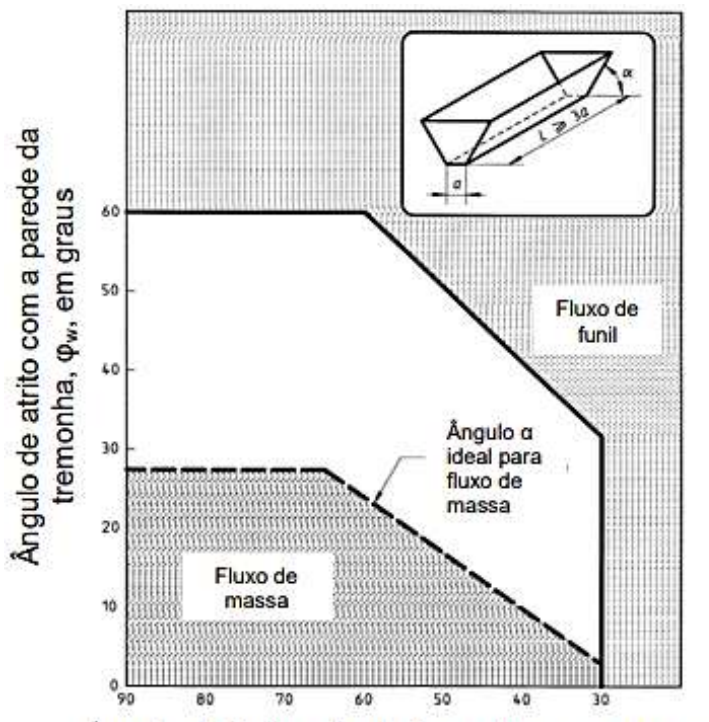

Ângulo de inclinação da tremonha, $\alpha$, em graus

Fonte: Paula (2020). 
Figura 5. Determinação do tipo de fluxo pela EN 1991-4 (2006).

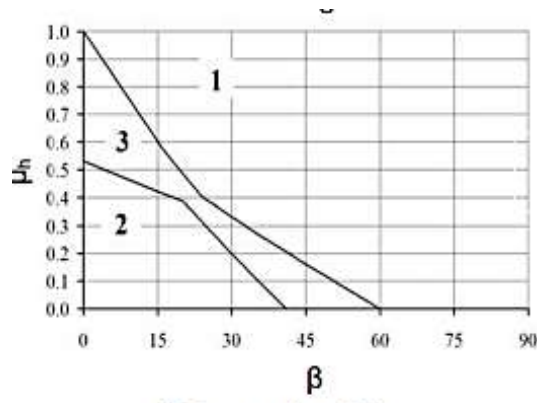

a) Tremonha cônica

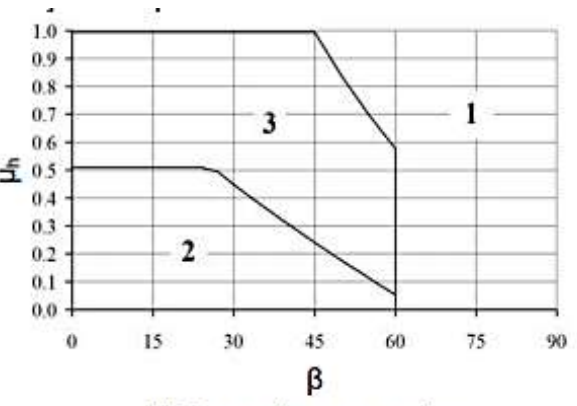

b) Tremonha em cunha

Sendo:

$1=$ Fluxo de funil;

2 = Fluxo de massa;

$3=$ Fluxo de massa ou funil;

$\beta=$ Ângulo de inclinação da tremonha;

$\mu_{h}=$ Coeficiente de atrito.

Fonte: Paula (2020).

Figura 6. Determinação do tipo de fluxo pela AS 3774 (1996).
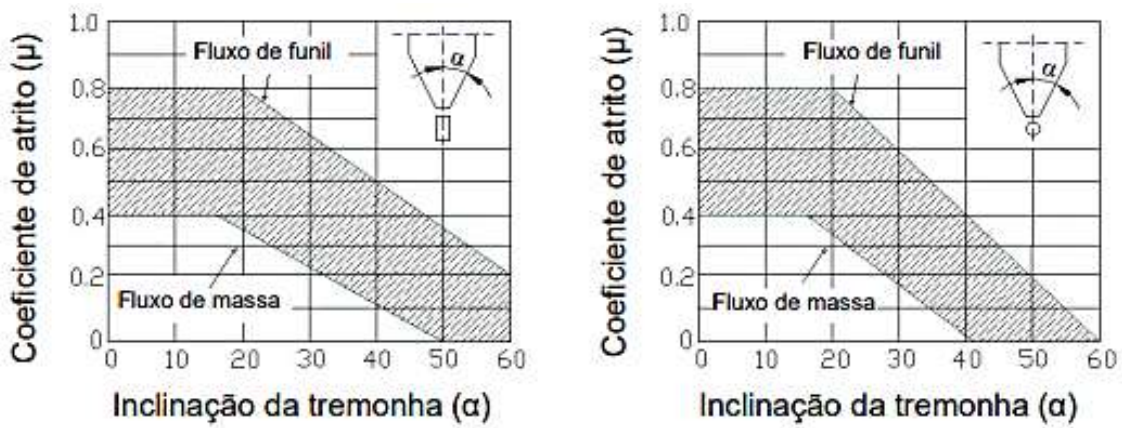

Legenda:

Zona de fluxo instável

Fonte: Paula (2020).

\subsection{Obstruções do fluxo}

A ocorrência de obstruções de fluxo em silos deve-se ao fato de o produto armazenado adquirir resistência suficiente, quando consolidado, para suportar o seu próprio peso (Ayres et al., 2020). Deste modo, no projeto de silos, o objetivo principal é garantir que o material armazenado fluirá sem que ocorram obstruções (Paula, 2020).

O ganho ou não dessa resistência depende da combinação de vários fatores, tais como: porcentagem e distribuição do tamanho das partículas finas, teor de umidade, tempo de armazenamento, presença de argilas ou talcos e natureza química do produto. Se o material ganhar resistência, podem ocorrer problemas de obstrução em tubo ou arco (coesivo ou mecânico), conforme Figura 7 - dependendo da inclinação e geometria da tremonha, dimensões do orifício de descarga, rugosidade da parede e o padrão de fluxo desenvolvido pelo produto (Cabrejos Marín, 2018).

Se durante a descarregamento do produto, nenhuma dessas obstruções ocorrerem, admite-se que acontecerá um fluxo satisfatório. As obstruções proporcionam sérios danos aos silos e sobretudo para as tremonhas, pois quando rompem, operam como pistões, comprimindo o ar existente na tremonha, levando a danos nas paredes laterais e orifício de descarga (Deckers, 2014). 
Figura 7. Tipos de obstruções do fluxo em silos.

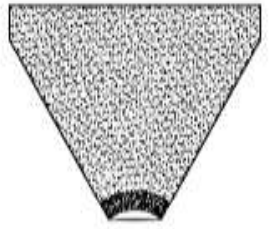

(a)

Arco coesivo

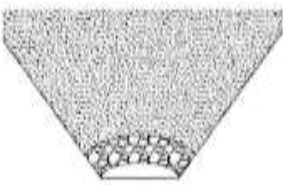

(b)

Arco mecínico

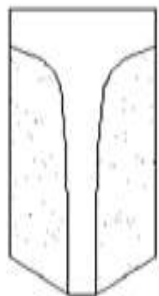

(c)

Obstruçĩo em tubo

Fonte: Teixeira (2006).

As obstruções de fluxo, tais como a formação de arcos coesivos e interrupção da descarga do silo, podem promover a parada total ou parcial do descarregamento, e se o silo estiver localizado no setor de produção, e ou distribuição, acarretará prejuízos devido ao aumento dos custos produtivos, causando a médio prazo um processo de descontinuidade da indústria (Silva, 2019).

Nesse sentido, a compreensão do comportamento do fluxo do produto é essencial para identificação de possíveis problemas de segregação e descarga. Observa-se em muitos casos a necessidade de melhoria do regime de descarga de fluxo a fim de obter-se tempo de armazenamento do produto suficientemente uniforme, evitando-se a formação de zonas estagnadas ou para reduzir a segregação (Silva, 2019).

\subsubsection{Efeito tubo}

O efeito tubo ocorre (Figura 8) substancialmente no fluxo de funil, sendo caracterizado pela estagnação e conservação de grande parte do produto adjacente ao tudo de descarga formado, ao longo de toda a altura do silo, proporcionando descarga incompleta do material (Cabrejos Marín, 2018). A ocorrência do efeito tubo dá-se em virtude de uma associação íntima entre as partículas de produtos coesivos, sendo descarregadas em silos dotados de tremonhas com elevado ângulo de inclinação em relação a vertical e paredes rugosas (Lopes Neto et al., 2007).

Cabrejos Marín (2018) afirma que é muito difícil produzir o fluxo desse material que fica estável em torno do canal por meios externos, como vibrações ou interferência manual. Dependendo da rugosidade das paredes e inclinação tremonha, o silo pode ou não esvaziar completamente. Deve-se garantir que o produto seja incapaz de adquirir resistência suficiente para suportar seu próprio peso, devido à consolidação. Em geral, os silos de fluxo de funil são adequados apenas para materiais granulares, de fluxo livre ou levemente coesos e quando a ocorrência de segregação não for importante (Cabrejos Marín, 2018). 
Figura 8. Efeito tubo.

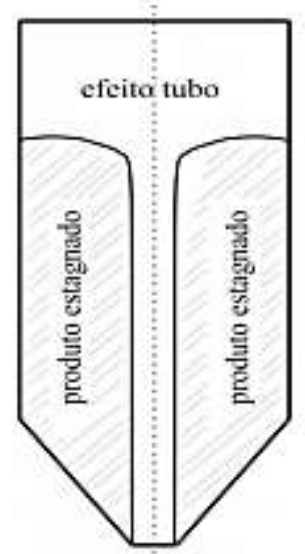

Fonte: Calil Júnior \& Cheung (2007).

Esse tipo de obstrução pode ser extremamente danoso à estrutura do silo se o material começar, a princípio na condição estagnada, a se mover no sentido axial. Caso isto ocorra, as primeiras camadas movidas provocarão sucção do ar na parte superior do corpo do silo e proporcionarão uma expulsão abrupta do ar contido no tubo, podendo causar deformações e ruptura das paredes, na zona de transição tremonha-corpo do silo, no orifício de descarga e dispositivos de descarregamento (Medeiros, 2012).

Lopes Neto e Nascimento (2013) estudaram a armazenagem em silos, de três produtos empregados no meio agrícola, sendo selecionados milho em grãos, milho triturado e farelo de soja. Os autores utilizaram um silo metálico em modelo reduzido de secção transversal semicircular com a face frontal fechada por uma parede de vidro translúcido, possibilitando a visualização do fluxo formado. Com o emprego de uma tremonha concêntrica de inclinação com a horizontal de $70^{\circ}$, constatou-se que para o milho triturado, o fluxo se iniciou com a formação de um canal de fluxo vertical e central propagandose no sentido ascendente, até atingir a superfície superior da massa armazenada. Os autores notaram, também, que o descarregamento ocorreu através de sucessivas tentativas de formação do efeito tubo e frequentes desmoronamentos das paredes laterais, sempre quando atingiam uma altura de formação média de $45 \mathrm{~cm}$, não sendo observado esse comportamento para os outros produtos analisados.

\subsubsection{Arqueamento}

O arqueamento é formado logo acima do orifício de descarga, interrompendo o fluxo (Oginni \& Fasina, 2018). Os arcos são diferenciados em coesivos ou mecânicos (Figuras 9 e 10), em razão ao processo de formação. No que se refere aos arcos coesivos, estes serão formados por materiais constituídos de partículas finas que, quando submetidas a um estado de tensão de compressão durante determinado tempo, adquirem resistência, formando obstruções capazes de interromper, parcial ou completamente o descarregamento (Lopes Neto et al., 2009).

Os arcos coesivos podem assumir distintas configurações, em virtude da geometria da tremonha empregada, sendo comum o aparecimento de arcos coesivos denominados de "ponte" em tremonhas em forma de cunha e de arcos abóboda ou domo em tremonhas de eixo simétrico (Medeiros, 2012). 
Figura 9. Obstruções do tipo arcos coesivos.

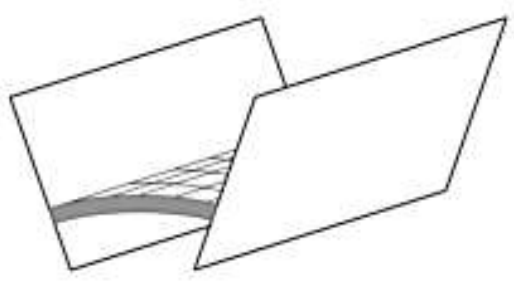

a) arco tipo "ponte"

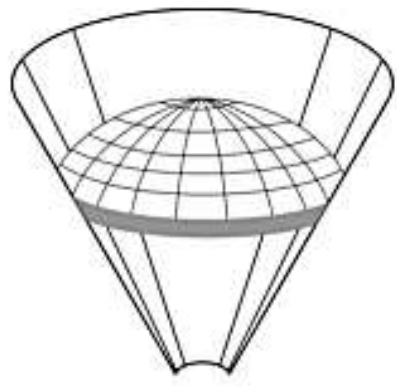

b) arco abóboda ou domo

Fonte: Medeiros (2012).

Quando há formação de arco coesivo em uma tremonha, a força resultante proveniente do peso do produto armazenado é transferida para as paredes da tremonha e, ao romper, essa força é direcionada ao corpo do silo (Lobato et al., 2016). Geralmente, produtos de granulometria mais fina e coesivos apresentam esse tipo de obstrução, exigindo maiores dimensões do orifício de descarga e inclinação da tremonha, a fim de se evitar problemas de arqueamento (Park et al., 2016).

Lopes Neto (2009) pontua que os arcos coesivos configuram um dos principais obstáculos enfrentados pelas indústrias que manuseiam produtos pulverulentos. Batista (2009) afirma que o tempo de armazenagem do produto deve ser analisado criteriosamente, pois afeta consideravelmente o tipo de fluxo e favorece a formação de arcos coesivos. Segundo o autor, quanto maior for o período do produto no interior do silo, maior será a ação da gravidade em todas as camadas do produto armazenado, consequentemente, maior será o nível de compactação de suas partículas, facilitando a formação de arcos.

Figura 10. Obstrução do tipo arco mecânico.

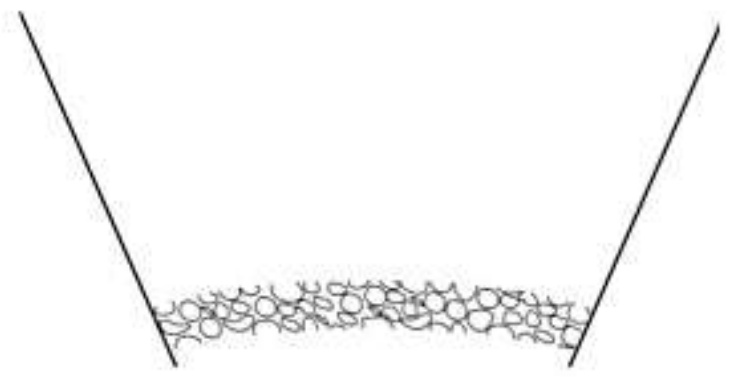

Fonte: Medeiros (2012).

Em contrapartida, a obstrução do tipo arco mecânico é ocasionada pelo intertravamento entre as partículas de granulometria maior quando comparadas à dimensão do orifício de descarga. Quando iniciado o fluxo, as partículas maiores são impedidas de se movimentar no sentido axial e de rotação entre si, principalmente quando os espaços vazios entre essas partículas são preenchidos por partículas de tamanhos menores (Ravenet, 1983).

\subsubsection{Descarga incompleta}

A descarga incompleta ocorre quando parte do material permanece no interior do silo após o descarregamento completo (Figura 11). Assim como no efeito tubo, suas consequências vão desde a redução da capacidade de armazenamento da estrutura, proporcionando perdas econômicas, até possíveis contaminações uma vez que uma mesma quantidade de produto 
pode permanecer no interior do silo por um período superior ao desejado (Lopes Neto, 2009), apresentando tendência a se deteriorar ou endurecer (Wójcik et al., 2012).

Figura 11. Descarga incompleta do silo.

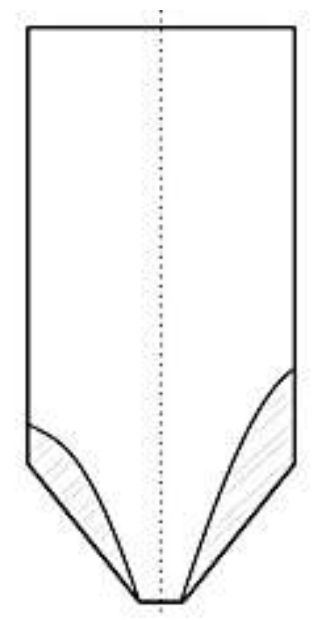

Fonte: Calil Júnior \& Cheung (2007).

\subsection{Inserts}

De acordo com o padrão de fluxo apresentado pelo produto quando armazenado, a estrutura do silo será mais solicitada, tornando evidente a necessidade do emprego de intervenções para minimizar estas ações e garantir um fluxo confiável, além de descarga homogênea exigida em determinadas aplicações industriais e agrícolas (Kobyłka et al., 2019). Para isso, várias soluções são conhecidas, como o uso de tremonhas lisas e íngremes, jateadores de ar comprimido, vibradores ou instalando inserts dentro do silo (Kobyłka et al., 2019).

As soluções de equipamentos como sistemas de injeção de ar e vibradores, envolvem um custo adicional, o que não é atrativo para o setor industrial (Ramírez-Gómez, 2016). Outra opção envolve reformas, podendo ser empregadas tremonhas mais íngremes e lisas, para reduzir significativamente o tamanho das zonas de estagnação e mudar o fluxo do funil para um fluxo de massa em silos existentes. No entanto, muitas vezes isso é impossível devido à falta de espaço disponível ou aos custos elevados (Wójcik et al., 2012).

Entre as possibilidades, os inserts surgem como alternativa simples e de baixo custo para garantir um fluxo confiável, reduzir as pressões da parede ou induzir o padrão de fluxo necessário, por atuar alterando os estados de tensão na zona de transição e proporcionar a redistribuição das partículas antes de atingirem o orifício de descarga (Kobyłka et al., 2019, Bandeira et al., 2020). Ayres et al. (2020) afirmam que a presença de insert na tremonha do silo, pode se constituir como relevante recurso para desobstrução do fluxo causado por arcos coesivos, garantindo melhor fluxo de escoamento.

Uma inserção é um dispositivo de um formato diferente colocado dentro do silo, geralmente na seção da tremonha, cujo objetivo principal é expandir a largura do canal de fluxo em um silo de fluxo em funil até a largura do silo para se aproximar do fluxo de massa total (Slominski et al., 2007; Hartl et al., 2008). Uma grande variedade de configurações de inserts é empregada (Figura 12), por exemplo, formas básicas, como cones, discos ou anéis, e mais elaboradas, como cone invertido, cone duplo e cone-em-cone (Hartl et al., 2008; Wójcik et al., 2012; Kobyłka et al., 2019). 
Figura 12. Tipologias de inserts.

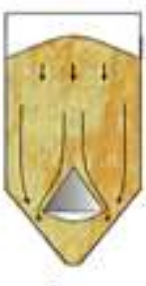

Cone

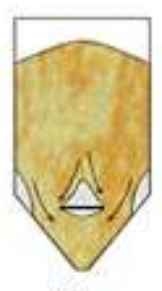

Plano

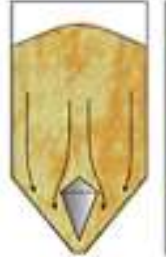

Duplo cone

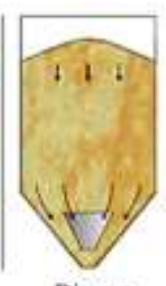

Binsert

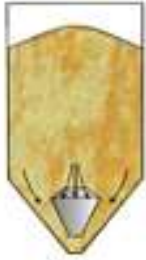

Duplo cone aberto

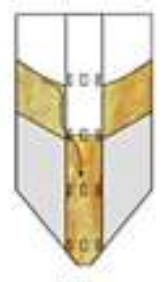

Tubo

central

Fonte: Hartl et al. (2008).

O design dos inserts é complexo, pela variação de parâmetros a serem definidos, como a seleção da localização do insert (altura sobre a saída), como fixá-los nas paredes do silo (seleção do tipo de reforço) ou qual forma de inserção seria melhor (Ramírez-Gómez, 2020). Estudos demonstram que inserts de cone duplo e de cone duplo invertido são os mais promissores para promoção do fluxo mássico e redução das pressões dinâmicas (Ding et al., 2015; Li et al., 2016), desde que apresentem um diâmetro máximo significativamente superior a $25 \%$ do diâmetro da tremonha (por exemplo, 50\%) (Wójcik et al., 2012).

Contudo, há considerações de que a relação de 30\% com as dimensões da tremonha, é estimada como a máxima a ser utilizada, pois ao ultrapassar desta relação o insert pode provocar problemas de obstrução do fluxo (Bandeira et al., 2020). Simulações numéricas ilustram que uma razão de 2:7 entre o diâmetro máximo da inserção e o diâmetro do silo são cruciais para o melhor efeito, independentemente do tipo de insert (Ding et al., 2003).

As geometrias de cone duplo, cone-em-cone (binsert $\left.{ }^{\circledR}\right)$ e cone invertido apresentam o emprego mais frequente (Figura 13), porém, essa prática é realizada com êxito limitado, pois critérios realistas com relação ao tipo, tamanho e localização dos inserts a serem cumpridos para obter fluxo de massa ainda são escassos (Cox et al., 2005; Silva, 2019). Entre essas três geometrias (cone duplo, cone-em-cone e cone invertido) simulações numéricas evidenciaram que o cone duplo parece ser o melhor em termos de promoção de fluxo mássico (Ding et al., 2003).

Figura 13. Diagrama esquemático de tremonha cônica com insert cone-em-cone (a) cone invertido (b) cone duplo (c).

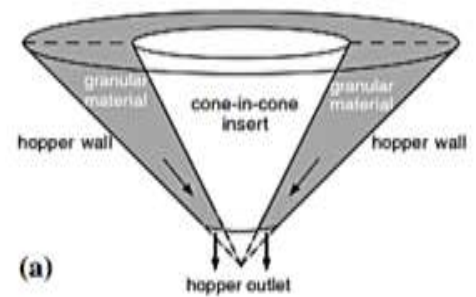

(b)

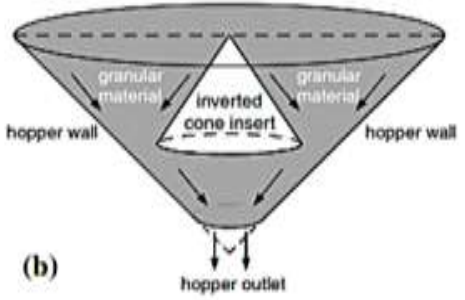

Fonte: Cox et al. (2005).

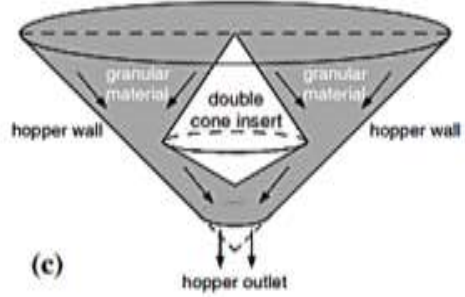

(c)

Apesar de muitas pesquisas, ainda não há recomendações detalhadas em normas de como calcular as cargas nos inserts e sua influência na distribuição de pressão ou no padrão de fluxo (Hammadeh et al., 2019; Kobyłka et al., 2020). As interações entre o produto armazenado e os inserts permanecem obscuras devido às dificuldades na descrição das pressões, que é indefinida devido à presença de atrito e depende do histórico de tensões (Kobyłka et al., 2019).

Outro fator a ser considerado é a localização adequada do insert, desempenhando um papel crucial na obtenção da correção desejada do padrão de fluxo. As inserções em silos são geralmente colocadas dentro da tremonha (Hartl et al., 2008), o posicionamento muito baixo ou acima da zona de transição entre a parede e tremonha pode aumentar o arqueamento, 
diminuir a taxa de descarga, bloquear o fluxo do produto (Hammadeh et al., 2019; Kobyłka et al., 2019) ou até comprometer a estrutura com distribuição desigual das pressões que geram cargas assimétricas no descarregamento (Kobyłka et al., 2020).

A zona de transição entre corpo do silo e tremonha é apontada como local ideal para posicionamento do insert, alterando o estado de tensão na zona de transição física, consequentemente facilitando o fluxo (Wojcik et al., 2012), contudo, o procedimento para encontrar o formato, tamanho e colocação adequados é comumente por tentativa e erro (Li et al., 2016). Recomenda-se que todas as inserções sejam colocadas em uma posição simétrica em relação ao eixo central do silo (Wojcik et al., 2012).

\subsection{Fluxo em silos com inserts}

Aplicação de inserts para melhorar os padrões de fluxo do produto durante a descarga foi originalmente proposta por Johanson \& Kleysteuber (1996), evidenciando que a geometria tipo cone invertido localizado em uma posição específica acima do orifício de descarga, reduziu significativamente o tamanho das zonas de estagnação durante o fluxo de funil (Wojcik et al., 2012).

A análise de três tipos de inserts em silo piloto com tremonha para areia (Figura 14) demonstrou que todos os modelos provocaram alteração do fluxo de funil em fluxo de massa, embora a velocidade do fluxo obtida tenha sido diferente na seção transversal em cada caso; para a inserção do tipo cone-em-cone, o material se moveu mais rápido acima do insert do que ao longo da parede; com o cone invertido, a areia se moveu mais rapidamente nas regiões entre a parede e a região intermediária acima do insert e para o tipo cone duplo, o material se moveu mais rápido próximo a parede (Slominski et al., 2007).

Figura 14. Silo modelo para análise de fluxo com inserts aplicados: a) cone em cone, b) cone invertido, c) cone duplo (unidades em mm).

a)

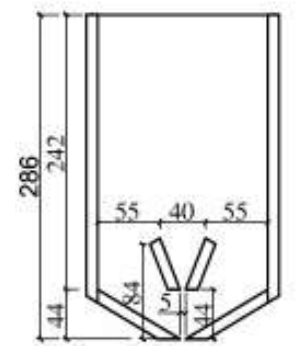

b)

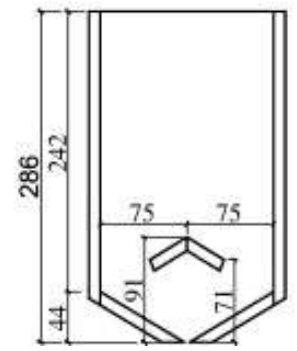

c)

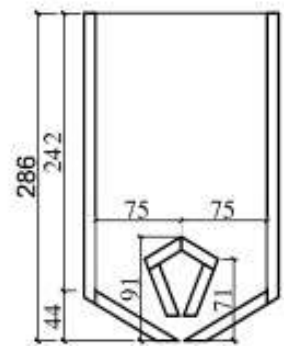

Fonte: Slominski et al. (2007).

O efeito tubo ocorre substancialmente no fluxo de funil, sendo caracterizado pela estagnação e conservação de grande parte do produto adjacente ao tudo de descarga formado, ao longo de toda a altura do silo, proporcionando descarga incompleta do material (Cabrejos Marín,2018).

Esse efeito apresentou-se durante o fluxo de areia em um silo cilíndrico construído em inox, com 8 metros de altura e 2,5 m de diâmetro $(\mathrm{H} / \mathrm{D}=3,2)$, equipado com tremonha de inclinação $45^{\circ}$, sem presença de insert; ao passo que, com instalação de insert tipo cone-em-cone o canal de fluxo alargou-se consideravelmente, para as oito posições experimentadas, contudo, o fluxo de massa não foi alcançado em nenhuma das configurações testadas (Härtl et al., 2008). Resultado semelhante foi obtido ao analisarem o efeito de insert tipo cone duplo em silo cilíndrico de aço inox de relação H/D igual a 3, dotado de tremonha (inclinação $45^{\circ}$ ), carregamento e descarregamento concêntrico de areia fina; obtendo-se fluxo de funil no silo sem a inserção e aumento considerável do canal de fluxo com a instalação do insert cone duplo, semelhante a um fluxo funil 
expandido (Ding et al., 2011).

Inserts de diversas geometrias (cone duplo, cone-em-cone, cone-em-cone duplo e cone invertido) e tamanhos (25, 35 e 50\% do diâmetro da tremonha) foram testados em um silo metálico de relação H/D igual a 3,6, dotado de tremonha cônica concêntrica de $44^{\circ}$ (ângulo de inclinação com a vertical) e $0,1 \mathrm{~m}$ (diâmetro orifício de descarga) para análise do fluxo de areia; a geometria de cone invertido com o maior tamanho (50\%) foi a mais eficiente para promover o fluxo de massa, e para os testes sem inserções, o fluxo funil foi obtido com a formação de canal de fluxo estreito no centro do silo e amplas zonas estagnadas ao longo das paredes do silo (Wójcik et al., 2012) .

A instalação de insert tipo cone duplo (Figura 15 (a) e (b)) reduziu significativamente os problemas de fluxo observados em silos com tremonhas de 33,5 e 45 , tais como rathole, interrupções e zonas estagnadas; após a o emprego do insert o produto movia-se uniformemente mantendo a superfície plana e toda material foi descarregado continuamente e sem interrupção (Ding et al., 2015).

Figura 15. Padrões de fluxo no silo com tremonhas de 33,5 e $45^{\circ}$ com inserts tipo cone duplo (a) e (b) e sem inserts (d) e (e) durante o descarregamento.

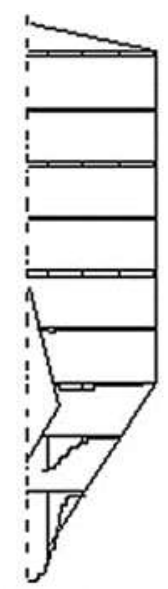

(a) $\theta=33.5^{\circ}$

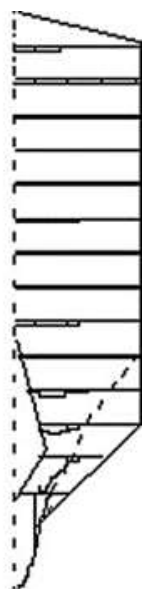

(b) $\theta=45^{\circ}$ (d) $\theta=33.5^{\circ}$

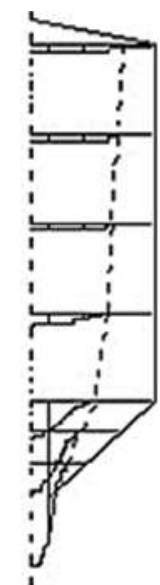

(e) $\theta=45^{\circ}$

Fonte: Ding et al. (2015).

Essas obstruções podem ser extremamente danosas à estrutura do silo se o material começar, a princípio na condição estagnada, a se mover no sentido axial. Caso isto ocorra, as primeiras camadas movidas provocarão suç̧ão do ar na parte superior do corpo do silo e proporcionarão uma expulsão abrupta do ar contido no tubo, podendo causar deformações e ruptura das paredes, na zona de transição tremonha-corpo do silo, no orifício de descarga e dispositivos de descarregamento (Medeiros, 2012).

A promoção do fluxo do material que fica estável em torno do canal por meios externos, como vibrações ou interferência manual é muito difícil (Cabrejos Marín, 2018). Salientando-se que se forem empregados dispositivos mecânicos, como vibradores, a abertura do orifício de descarga deverá ser projetada com um coeficiente de segurança, em função dos efeitos desfavoráveis das vibrações (Palma, 2005).

Para ração avícola a utilização de inserts em tremonhas durante a descarga apresentou-se como uma boa solução ao problema de formação de abóbadas sobre o orifício de descarga em silos metálicos verticais, proporcionado pelas mudanças nos estados de tensões ativo e passivo e, por consequência, a promoção do fluxo de massa, como pode ser observado na Figura 16, demonstrando uma alternativa eficaz pela não formação de arcos coesivos e a promoção de descarga uniforme e ininterrupta (Nascimento \& Bandeira, 2017). 
Figura 16. Sequência fotográfica da descarga do silo com e sem emprego de inserts.

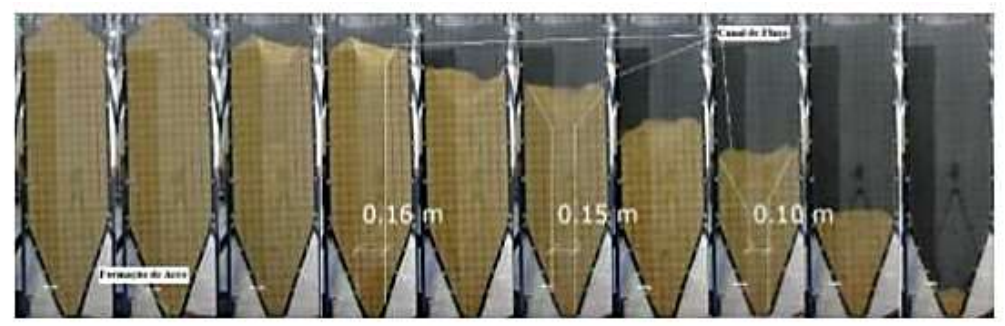

(a) Descarregamento do silo sem emprego de insert na tremonha.

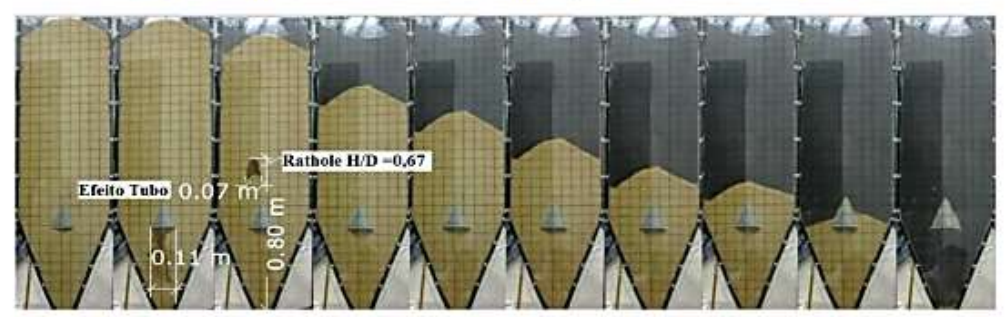

Fonte: Nascimento e Bandeira (2017).

Quando há formação de arco coesivo em uma tremonha, a força resultante proveniente do peso do produto armazenado é transferida para as paredes da tremonha e, ao romper, essa força é direcionada ao corpo do silo (Lobato et al., 2016). Geralmente, produtos de granulometria mais fina e coesivos apresentam esse tipo de obstrução, exigindo maiores dimensões do orifício de descarga e inclinação da tremonha, a fim de se evitar problemas de arqueamento (Park et al., 2016), ou então, emprego de inserts, como apresentado por Nascimento e Bandeira (2017).

A verificação da homogeneidade da mistura de sementes de mostarda após descarregamento em silos variando a inclinação da tremonha $(20,24,30,45,60$ e 90 $)$, rugosidade da parede e a adição de três diferentes inserçães de correção de fluxo (Figura 17), demonstrou que, embora a rugosidade da parede tenha exercido grande influência na mistura e no tamanho da zona de produto estagnado (a região de "não fluxo" em um silo de fluxo em funil), a adição de inserções (independente da geometria) apresentaram maior efeito na redução de zonas estagnadas e melhoraram a taxa de mistura do material durante a descarga, sendo fator importante em muitos processos industriais que necessitam de dosagens precisas e homogêneas (Fullard et al., 2020). 
Figura 17. Desenhos em escala das três inserções testadas. Superior: Esférico, Intermediária: cone duplo grande, Inferior: cone duplo pequeno.

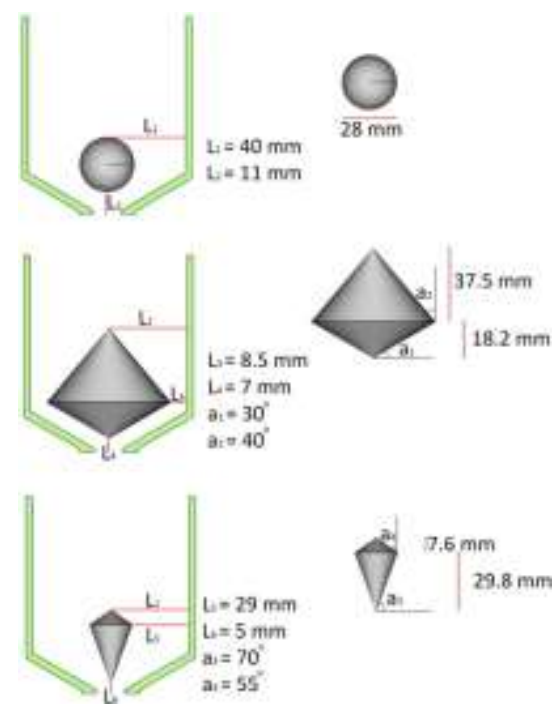

Fonte: Fullard et al. (2020).

\subsection{Ações em silos verticais}

Como todas as outras estruturas de engenharia, o ponto de partida para análise estrutural no projeto de silos é a determinação das ações atuantes durante o ciclo de vida da estrutura, as quais podem ser classificadas em permanentes, variáveis e excepcionais (Tascón, 2017; Mehretehran \& Maleki, 2018). As ações permanentes incluem o peso próprio do silo e dos equipamentos fixados nele. As cargas variáveis referem-se aos produtos armazenados, elementos estruturais que sofrem vibrações e estão fixados no silo, como por exemplo, as correias transportadoras, ações do vento etc. (Mehretehran \& Maleki, 2018). As ações excepcionais englobam os prováveis impactos de veículos e pressões decorrentes da explosão de pós.

Uma particularidade das ações que atuam nos silos encontra-se na avaliação das cargas de carregamento e as cargas induzidas pelo descarregamento do produto no silo. Cada um dos processos, seja carregamento, armazenamento ou descarga, geram tensões na estrutura com magnitudes bastante diversas. É de extrema importância para o dimensionamento adequado do silo que se conheça as distribuições de carga do material armazenado exercida na estrutura, sendo depende do padrão de fluxo (Wójcik et al., 2017).

$\mathrm{Na}$ condição de carregamento e armazenamento (momento anterior ao início do descarregamento), o produto encontra-se submetido a um estado de tensões denominado de estado ativo, caracterizado por apresentar a tensão principal máxima na direção vertical, coincidente com o eixo do silo, e a tensão mínima na direção horizontal, chamado de pressões estáticas (Paula, 2020).

A partir do instante em que se inicia o descarregamento do produto armazenado, essa configuração de tensões modifica, passando a maior tensão principal a atuar na direção horizontal e a menor tensão principal, na direção vertical. Neste momento, têm-se o estado passivo de tensões e é caracterizado pela expansão vertical do produto e compressão horizontal (deformação plástica), sendo conhecido como pressões dinâmicas (Figura 18) (Paula, 2020). Acredita-se que estados não uniformes de tensão em silos de grãos sejam a causa de muitas falhas estruturais (Kobyłka et al., 2020). 
Figura 18. Pressões atuantes nas paredes do silo nas fases de carregamento, armazenamento e descarga.

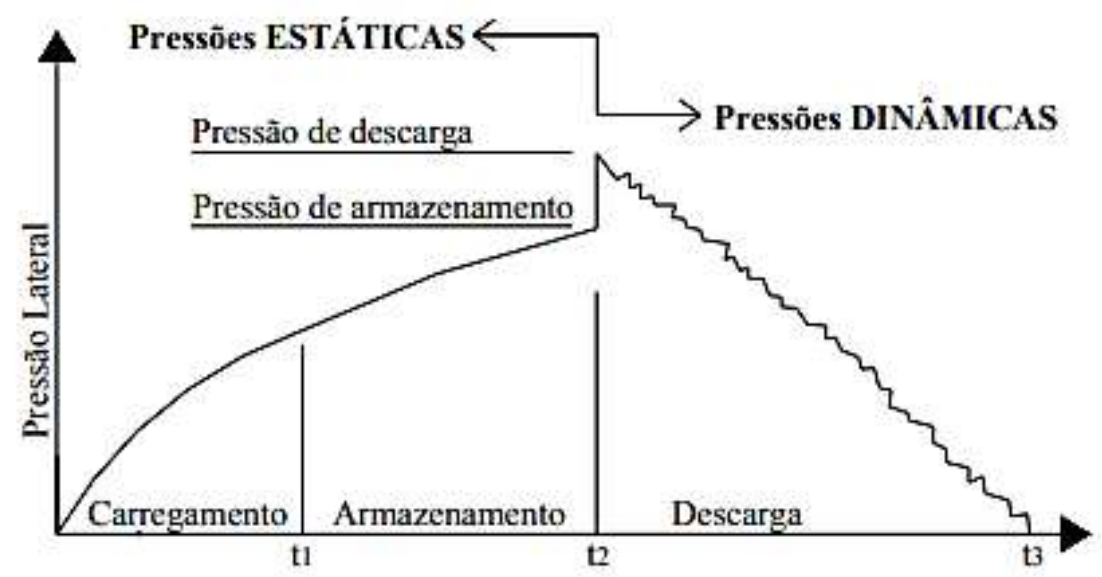

Fonte: Deckers (2014).

\subsection{Pressões em silos}

Como a integridade estrutural do silo depende da quantidade de pressão exercida pelo material armazenado, é fundamental compreender e quantificar as pressões no projeto (Oginni \& Fasina, 2018). Nas paredes verticais atuam pressões normais e paralelas, denominadas pressões horizontais $(\mathrm{Ph})$ e pressões de atrito $(\mathrm{Pw})$, respectivamente. No fundo do silo atuam as pressões verticais $(\mathrm{Pv})$, sendo decompostas em pressões normais $(\mathrm{Pn})$ e tangenciais $(\mathrm{Pt})$ às paredes da tremonha (Figura 19).

Figura 19. Pressões geradas pelo produto armazenado.

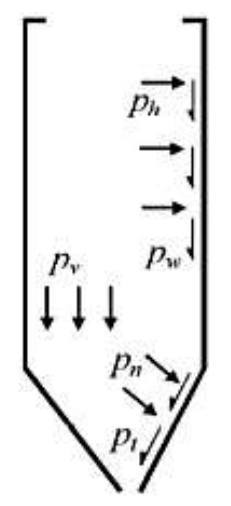

Fonte: EN 1991-4 (2006).

A pressão de atrito é distribuída na superfície das paredes e equilibra parte do peso do produto, resultando em esforços de compressão nas paredes (Palma \& Calil Junior, 2008). As pressões horizontais exercidas nas paredes pelo produto não aumentam indefinidamente com a altura do silo, como ocorrem no caso das pressões hidrostáticas, justamente pela existência deste atrito, fazendo com que apresentem um crescimento que tende a um valor máximo exponencial (Figura 20). 
Figura 20. Pressões estática e dinâmica em silo.

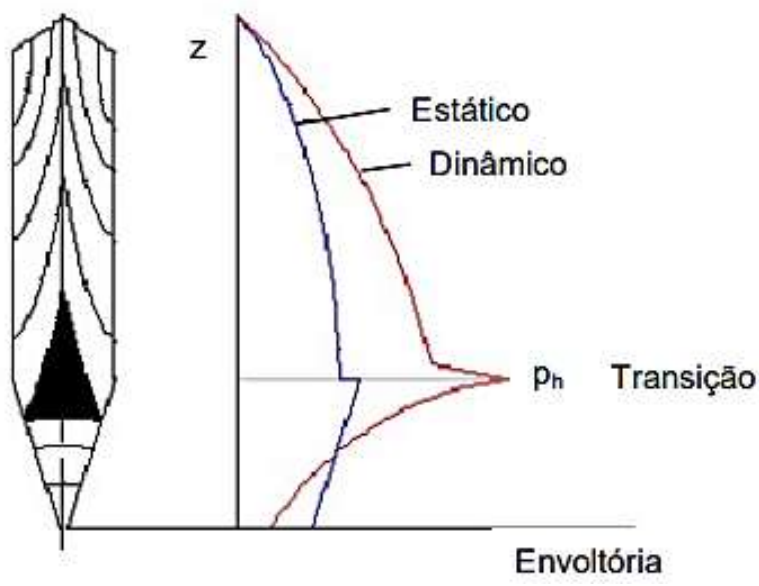

Fonte: Palma (2005).

A determinação da magnitude e distribuição das pressões durante a descarga é particularmente desafiadora, pois a pressão tende a exibir flutuações significativas e suas distribuições ao longo das paredes do silo dependem intimamente do padrão de fluxo desenvolvido ao longo do silo (Wang et al., 2015). Outros fatores que parecem contribuir para a assimetria de cargas dentro dos silos são a variabilidade na densidade do produto armazenado, do coeficiente de atrito com a parede, anisotropia do ângulo de atrito interno e a presença de inserts (Horabik et al., 2016).

A abertura do orifício de descarga gera uma diminuição na pressão vertical que pode ser acompanhada por um aumento na pressão horizontal dependendo da relação altura-diâmetro (H/D), geometria e do tamanho do silo, sendo encontrados picos de pressão na faixa de 1,1 a 3,9 (Kobyłka et al., 2017). As pressões geradas por grãos de trigo em um silo cilíndrico metálico de paredes lisas com relação H/D igual a 2, foram máximas nos primeiros segundos da descarga, atingindo diferenças acima de $20 \%$ entre as fases estática e dinâmica (Ruiz et al., 2012).

A variação do fluxo durante a descarga implica em variação de pressão não associada e o estado de sobrepressão durante a descarga deve-se principalmente à compactação do produto em determinadas áreas do silo e em muito menor grau à dilatância, além disso, valores de pressão obtidos durante a descarga podem ultrapassar, em alguns casos, os fornecidos pelo método de cálculo propostos pelas normas estrangeiras (Couto et al., 2013a e 2013b).

Apesar da predição das pressões estáticas e dinâmicas constituírem objeto de estudo por vários pesquisadores e muito progresso tenha sido alcançado, ainda não podem ser perfeitamente estimadas (Sun et al., 2018), entretanto, algumas metodologias de cálculos são aceitas por apresentarem boa aproximação, destacando-se as formulações desenvolvidas por Janssen (1985), Reimbert (1943), Jenike e Johanson (1968) e Walker (1966).

\subsection{Pressões em silos com inserts}

As pressões nas paredes podem ser modificadas com a presença de inserts (Ramírez-Gómez, 2020), sendo sua estimativa pré-requisito para garantir a integridade estrutural. Além disso, não há possibilidade de transferir as regras de projeto existentes para silos sem inserts para as estruturas com inserções, devido a um padrão de fluxo diferente (Wójcik et al., 2012).

Nos primeiros trabalhos publicados sobre o assunto, há indicação de um aumento significativo das tensões da parede no início da descarga com insert quando localizado na parte superior da tremonha, ao passo que, o pico de pressão não foi registrando com a instalação de insert na parte inferior da tremonha, próximo à saída do silo (Johanson \& Kleysteuber, 1996).

As cargas estáticas e dinâmicas nas paredes de silos com inserts apresentam uma dependência aproximadamente 
linear com a localização da inserção; quanto maior a altura em relação à zona de transição entre parede e tremonha, mudanças se desenvolvem no campo de tensões durante o carregamento e isso se reflete em cargas de parede elevadas (Schuricht et al., 2009).

A presença de insert tipo cone-em-cone em um silo metálico de relação H/D igual a 3 e tremonha cônica com inclinação de $45^{\circ}$ para areia gerou um aumento significativo na pressão normal da parede durante a descarga, o que provavelmente foi causado pelo canal de fluxo estar mais próximo da parede do silo quando a inserção foi implantada, sendo as pressões dinâmicas registradas em silo sem insert de 15 a $20 \%$ superiores as pressões estáticas e com insert houve aumento de 25 a 60\%, em contrapartida, a pressão dinâmica da tremonha reduziu com inserção (Härtl et al., 2008).

No entanto, deve-se ter cuidado ao tirar conclusões concretas sobre a magnitude das pressões de uma única linha meridional sensores, pois, há variação significativa de pressão ao redor da circunferência, lançando dúvidas sobre a prática comum de instalar uma única linha de células de pressão sem verificar a variação da pressão ao redor da circunferência (Härtl et al., 2008). A variação de pressão em torno da circunferência não ocorreu apenas para os testes com insert, mas também para os ensaios sem insert, portanto, o pico na pressão possivelmente não ocorreu devido apenas à excentricidade na geometria do insert ou ao seu posicionamento na tremonha (Härtl et al., 2008).

A presença de insert tipo cone duplo em silo metálico de relação H/D igual a 3 com tremonha de $45^{\circ}$ e produto experimental areia fina, não alterou de forma significativa as pressões estáticas e dinâmicas quando comparadas aos ensaios sem insert, sendo observados efeitos notórios somente na zona de transição e tremonha, com aumento substancial da pressão normal próxima à transição e redução considerável na parte inferior da tremonha (Ding et al., 2011).

Um estudo foi conduzido para avaliar o efeito de obstrução plana (2D) e de bloco (3D) fixada na parede de silo com grãos de trigo como material armazenado, e a avaliação da razão de pressão horizontal com vertical (K) mostrou que a inserção pode levar à mudança não apenas da pressão da parede na área mais próxima de tal objeto, mas também pode afetar a distribuição de carga em toda a estrutura (Kobyłka \& Molenda 2014). As pressões horizontais abaixo dos inserts, tanto no estado ativo quanto passivo, foram notoriamente menores do que no silo sem insert (Kobyłka \& Molenda, 2014).

Análises sobre as cargas exercidas em inserts em forma de discos, cones e cilindros para grãos de trigo evidenciaram que, insert com superfície superior plana, uma zona de material estagnado se forma em cima dela, e essa zona tem um formato altamente instável durante a descarga, gerando uma carga vertical maior no insert tipo disco do que na superfície lisa e afiada do cone (Kobyłka et al., (2019). Uma diminuição significativa na pressão das paredes foi observada abaixo da altura de colocação dos inserts, independentemente da geometria (Kobyłka et al., 2019).

A forte concentração de cargas em inserts com superfícies planas também foi observada por Moysey et al. (2013), Samsu et al., 2018 e Kobyłka et al. (2020). Essa concentração de forças em superfícies lisas provavelmente reflete o ordenamento das partículas,

A pressão dinâmica durante a descarga de grãos de milho em silo metálico de relação $\mathrm{H} / \mathrm{D} \cong 2$, com o emprego de insert tipo cone duplo em quatro posições não provocou aumento da pressão dinâmica em três das posições testadas, ao contrário, reduziu o valor de pressão resultante tanto na parede do silo quanto na tremonha e a melhor posição para essa geometria de insert foi para a relação (h1/h2 = 1; onde h1 é a altura da base de inserção em relação ao orifício de descarga (Fig. 21) e h2 é a altura da tremonha.), provocando pressões tanto na parede quanto na tremonha menores que as pressões resultantes sem emprego do insert (Hammadeh et al., 2019). 
Figura 21. Posições do insert e transdutores de pressão no silo experimental.

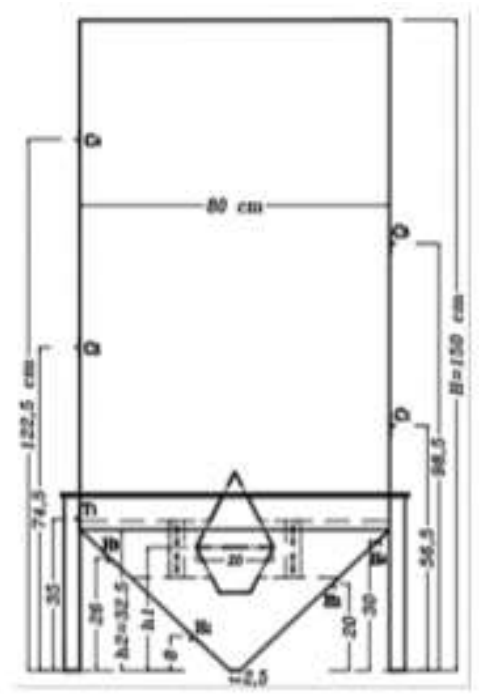

Fonte: Hammadeh et al. (2019).

A análise dos efeitos da descarga excêntrica e de uma inserção de anel sugere que a colocação cuidadosa de insert pode reduzir os momentos de flexão na parede do silo gerados pelo descarregamento excêntrico. Isso possibilita a execução de projetos de silo que empreguem a descarga excêntrica sem riscos de colapso (Kobyłka et al., 2020).

Conclui-se que a influência das inserções internas no padrão de fluxo, bem como as cargas sobre elas, tem sido estudada há décadas, mas nenhum método de projeto geral foi proposto, pelo fato de existirem numerosas combinações entre geometrias de silo, geometrias de inserts e distintas características de produtos armazenáveis, impedindo a obtenção de tais diretrizes apenas por experimentação (Kobyłka et al., 2020).

No entanto, com o desenvolvimento substancial da tecnologia computacional nas últimas décadas, alguns efeitos que não poderiam ser tratados de forma eficiente com as abordagens disponíveis anteriormente, podem ser facilmente simulados por meio de métodos numéricos (Kobyłka et al., 2020), e nesse contexto, as simulações numéricas surgem como alternativas econômicas para o fornecimento de dados promissores.

\section{Considerações Finais}

Para a seleção da geometria, dimensões e posicionamento adequado de insert no interior de um silo a fim de obter-se melhorias no fluxo do produto e redução de cargas transferidas as paredes da estrutura durante o descarregamento, destaca-se a necessidade de ter-se o conhecimento e caracterização das propriedades físicas do produto a ser armazenado, bem como do comportamento do fluxo e das pressões dinâmicas da parede, aliados a simulações numéricas como uma ferramenta de design da inserção.

É interessante destacar que os dados apresentados são úteis não apenas para o projeto de silos, mas também para a validação de modelos matemáticos. Uma vez validados, os modelos matemáticos podem ser aplicados em situações em que a verificação experimental não é possível ou econômica.

Novas pesquisas devem ser realizadas acerca do tema, uma sugestão para novos estudos seria a determinação de critérios com relação ao tipo, tamanho e localização dos inserts em silos para redução da segregação em produtos com granulometria heterogênea. 


\section{Agradecimentos}

Ao Instituto de Ciências Agrárias e Ambientais (ICAA) da Universidade Federal de Mato Grosso, por ter concedido afastamento para cursar doutorado à primeira autora.

Ao Programa de Pós-Graduação em Engenharia Agrícola da Universidade Federal de Campina Grande pelo apoio na realização deste trabalho.

\section{Referências}

AS- Australian Standart. (1996) AS 3774: Loads on bulks containers.

Ayres, G. D. J., do Nascimento, J. W. B. \& Mascarenhas, N. M. H. (2020). Rompimento de arcos coesivos em silos verticais com emprego de pneumaticos: Uma revisão bibliográfica. Revista de Ciências Agrárias, 2020,43(4): 390-395.

Bandeira, D. J. A., Nascimento, J. J. S., \& Nascimento, J. W. B. (2020). Análise do fluxo de ração avícola em silos verticais esbeltos com insert de cone invertido . Research, Society and Development, 9(11), e63091110369.

Baroni, G. D., Benedeti, P. H. \& Seidel, D. J. (2017). Cenários prospectivos da produção e armazenagem de grãos no Brasil. Revista Thema, 14(4), 55-64.

Batista, C. S. (2009) - Estudo teórico e experimental do fluxo de sólidos particulados em silos verticais. Tese de Dou-torado, Campina Grande, Universidade Federal de Campina Grande.

Cabrejos Marín, F. (2018). Gravity reclaim stockpiles: What you need to know. Particulate Science \& Technology, 36(4), 473-480.

Calil Júnior C (1990) Recomendações de fluxo e de cargas para o projeto de silos verticais. Tese (Livre Docência) - Escola de Engenharia de São Carlos, Universidade de São Paulo.

Calil Júnior, C. \& Cheung, A. B. (2007). Silos: Pressões, fluxo, recomendações para o projeto e exemplos de cálculo. 232p.

CONAB - Companhia Nacional de Abastecimento (2020) Perspectivas para a agropecuária Safra 2020/2021. Perspec. agropec., safra 2020/21, 1-75. http://www.conab.gov.br.

CONAB - Companhia Nacional de Abastecimento (2021) Acompanhamento safra brasileira de grãos, v.8- Safra 2020/21, n. 4 - Quarto levantamento, Brasília, p. 1-85, Janeiro 2021. ISSN 2318-7913. https://www.conab.gov.br/info-agro/safras/graos/boletim-da-safra-de-graos.

Couto, A., Ruiz, A., Herraez, L., Moran, J. \& Aguado, P. J. (2013b). Measuring pressures in a slender cylindrical silo for storing maize. Filling, static state and discharge with diferente material flow rates and comparison with Eurocode 1 part 4. Computers and Electronics in Agriculture, 96, 40-56.

Couto. A., Ruiz, A. \& Aguado, P. J. (2013a). Experimental study of the pressures exerted by wheat stored in slender cylindrical silos, varying the flow rate of material during discharge.Comparison with Eurocode 1 part 4. Powder Technol 237: 450-467.

Cox, G., McCue, S., Thamwattana, N. \& Hill, J. (2005). Perturbation solutions for flow through symmetrical hoppers with inserts and asymmetrical wedge hoppers. Journal of Engineering Mathematics, 52, 63-9.

Deckers, H. P. F. (2014). Estudo teórico de pressões em silos esbeltos prismáticos com descarga excêntrica. UFLA. Tese de Dou torado.

Ding S., Lib H. L I., Ooi J. Y. \& Rotter, J. M. (2015). Prediction of flow patterns during silo discharges using a finiteelement approach and its preliminary experimental verification. Particuology, 18 (1), 42-49.

Ding, S., Dyrøy, A., Karlsen, M., Enstad, G. G. \& Jecmenica, M. (2011). Experimental Investigation of Load Exerted on a Double-Cone Insert and Effect of the Insert on Pressure Along Walls of a Large-Scale Axisymmetrical Silo. Particulate Science \& Technology, 29 (2), $127-138$.

Ding. S., De Silva, S. \& Enstad, G. G. (2003) Effect of Passive Inserts on the Granular Flow from Silos Using Numerical Solutions. Particulate Science \& Technology, 21, 211-226, 2003.

EN 1991-4: EUROCODE 1. Actions on structures - Part 4: Silos and tanks. European Committee for Normalisation. 108 p.

Fullard, L. A., Godfrey, A. J. R., Manaf, M. F., Davies, C. E., Cliff, A. \& Fukuoka, M. (2020). Mixing experiments in 3D-printed silos, the role of wall friction and flow correcting inserts. Advanced Powder Technology, v. 31(5), 1915-1923.

Gallego, E., Ruiz, A. \& Aguado, P. J. (2015). Simulation of silo filling and discharge using ANSYS and comparison with experimental data. Computers and Electronics in Agriculture, 118, 281-289.

Hammadeh, H., Askifi, F., Ubysz, A., Maj, M. \& Zeno, A. (2019). Effect of using insert on the flow pressure in cylindrical silo. Studia Geotechnica et Mechanica, 41 (4), 177-183.

Hartl, J., Ooi, J.Y., Rotter, J.M., Wojcikb, M., Ding, S. \& Enstad, G.G. (2008). The influence of a cone-in-cone insert on flow pattern and wall pressure in a full-scale silo. Chemical engineering research and design, 86(4), 370-378.

Horabik, J. Parafiniuk, P. \& Molenda, M. (2016). Experiments and discrete element method simulations of distribution of static load of grain bedding at bottom of shallow model silo, Biosystems Engineering, 149, 60-71. 
Hsiau. S. S., Smida, J., Chyou, Y. P., Liu, T. C., Huang, T. C. \& Hsu, C. J. (2013). Impact of flow-corrective insert on flow patterns in twodimensionalmoving bed. Chemical Engineering and Processing, 73(1), 7-15.

IBGE - Instituto Brasileiro de Geografia e Estatística (2020) Levantamento Sistemático da Produção Agrícola - Estatística da Produção Agrícola. 144 p. https://biblioteca.ibge.gov.br/visualizacao/periodicos/2415/epag_2020_dez.pdf.

International Organization for Standart. ISO 11697. Bases for design of structures: Loads due to bulk materials. Switzerland: International Standard. London, 2012.

Janssen, H. A. (1895). Experiments on grain pressures in silos. Verein Deutscher Ingenieure, 39, 1045-1049.

Jenike, A. W., \& Johanson, J. R. (1968). Bin Loads. Journal of the Structural Division, 95(4), 1011-1042.

Johanson, J. R., \& Kleysteuber, W. K. (1996). Flow corrective inserts in bins. Chemical Engineering Progress, 62, 79-83.

Kobyłka, R. \& Molenda, M. (2014). DEM simulations of loads on obstruction attached to the wall of a model grain silo and of flow disturbance around the obstruction. Powder Technology, 256, 210-216.

Kobyłka, R., Horabik, J. \& Molenda, M. (2017). Numerical simulation of the dynamic response due to discharge initiation of the grain silo, International Journal of Solids and Structures, 106-107, 27-37.

Kobyłka, R., Molenda, M. \& Horabik, J. (2019). Loads on grain silo insert discs, cones, and cylinders: Experiment and DEM analysis. Powder Technology, v. 343(1), 521-532.

Kobyłka, R., Molenda, M. \& Horabik, J. (2020). DEM simulation of the pressure distribution and flow pattern in a model grain silo with an annular segment attached to the wall. Biosystems Engineering, 193(1), 75-89.

Koynov, S., Glasser, B. \& Muzzio, F. (2015). Comparison of three rotational shear cell testers: Powder flowability and bulk density. Powder Technology, 283, 103-112.

Li, Y., Gui, N., Yanga, X., Tua, J. \& Jianga, S. (2016). Effect of a flow-corrective insert on the flow pattern in a pebble bedreactor. Nuclear Engineering and Design, 300 (1), 495-505.

Lobato. J. C. M., F. Mascarenhas. F. P., Mesquita. A. L. A. \& Mesquita. A. L. A. (2016).Conical Hopper Design for Mass Flow - Case of red mud. Holos. 2 , $120-131$.

Lopes Neto, J. P., Nascimento, J. W. B., \& Lopes, F. F. M. (2012). Modelos De Previsão do Fluxo e Vazão De Descarga De Produtos Agrícolas. Revista Educação Agrícola Superior. 27 (1), 54-58.

Lopes Neto, J. P., \& Nascimento, J. W. B. (2013). Características de fluxo e projeto de tremonhas cônicas em silos verticais. Revista Brasileira de Engenharia Agrícola e Ambiental, 17(3), 339-345.

Lopes Neto, J. P., Nascimento, J. W. B. do, Silva, V. R. da, \& Lopes, F. F. de M. (2007). Propriedade de fluxo e característica de escoabilidade de rações avícolas para dimensionamento de silos. Ciência e Agrotecnologia, 31(3), 851-859.

Lopes Neto, J. P., Nascimento, J. W. B. do, Calil Junior, C. (2008). Análise estrutural de silos metálicos prismáticos. Ciência e Agrotecnologia, 32(4), 12521258 .

Lopes Neto, J. P. (2009). Análise teórico experimental das forças verticais e de atrito em silos cilíndricos. Engenharia de Processos, Universidade Federal de Campina Grande. Tese de doutorado.

Lopes Neto, J. P., Nascimento, J. W. B. \& Silva, V. R. (2009) - Efeito do tempo de armazenagem de rações avíco-las no dimensionamento de silos. Revista de Engenharia Agrícola, vol. 29, n. 2, p. 518-527.

López, J., Pastorello, I. M. \& Arce, A. I. C. (2014). Vazão facilitada de grãos de arroz de um silo cilíndrico usando "obstruções" esféricas ou cônicas. Revista Brasileira de Ensino de Física, 36(1), 1-5.

Mathews, J. C. \& Wu, W. (2016). Model tests of silo discharge in a geotechnical centrifuge, Powder Technology, 293, 3-14.

Medeiros, I. F. (2012). Características de fluxo e vazão de descarga em silos verticais. Dissertação de Mestrado. Universidade Federal de Campina Grande, Campina Grande, PB, Brasil.

Mehretehran, A. M. \& Maleki, S. (2018). 3D buckling assessment of cylindrical steel silos of uniform thickness under seismic action. Thin-Walled Structures, $131,654-667$.

Moysey, P. A., Rama Rao, N. V. \& Baird, M. H. I. (2013). Dynamic coefficient of friction and granular drag force in dense particle flows: Experiments and DEM simulations, Powder Technology, 248, 54-67.

Nascimento, J. W. B. \& Bandeira, D. J. A. (2017) - Descarga em silos verticais sem obstrução do fluxo com uso de inserts. In: Anais do Congresso Técnico Científico da Engenharia e da Agronomia. SOEA, p. 77-83.

Oginni, O. \& Fasina, O. (2018). Theoretical estimation of silo design parameters for fractionated loblolly pine grinds - Moisture content and particle size effects. Industrial Crops and Products, 123, 379-385.

Olivares, M. C. V., Benito, J. G., Uñac, R. O. \& Vidales, A. M. (2018). Towards a one parameter equation for a silo discharging model with inclined outlets. Powder Technology, 336, 265-272. 
Palma, G. \& Calil Júnior, C. (2008). Pressões e fluxo em silos esbeltos (H/D $\geq 1,5)$. Caderno de Engenharia de Estruturas,10, 129-150.

Palma, G. (2005). Pressões e fluxos em silos esbeltos (h/d $\geq 1,5$ ). Escola de Engenharia de São Carlos, Universidade de São Paulo. Dissertação de Mestrado.

Park, H. W., Kim, S. T., Choung, M. G., Han, W.-Y. \& Yoon, W. B. (2016). Flow Behavior of Adzuki Bean Flour. Journal of Food Process Engineering, 39(4), 366-376.

Paula, W. C. (2020). Influência da geometria de tremonhas concêntricas e excêntricas nos esforços de silos esbeltos metálicosUFLA. Tese de Doutorado.

Pereira, A. S., Shitsuka, D. M., Parreira, F. J. \& Shitsuka, R. (2018). Metodologia da pesquisa científica. [free e-book]. Santa Maria/RS. Ed. $\mathrm{UAB} / \mathrm{NTE} / \mathrm{UFSM}$.

Ramírez-Gómez, Á. (2016). Research needs on biomass characterization to prevent handling problems and hazards in industry. Particulate Science \& Technology, 34(4), 432-441.

Ramírez-Gómez, A. (2020). The discrete element method in silo/bin research. Recent advances and future trends. Particulate Science and Technology, 38(2), 210-227.

Ravenet, J. (1983) - Silos: flujo de vaciado de sólidos, formacion de bovedas. Editores Técni-cos Asociados, 330p.

Reimbert, M. A. (1943). Recherches novelles sur les efforts exercs par les matieres pulverulentos ensilees sur les parois des silos. Annales Institute Technique du Batiment et des Travaux Publics. I(11), 49-60.

Rodrigues, M. H. B. S., Sousa, V. F. O., Santos, G. L., Nobrega, E. P. \& Andrade, F. E. (2018). Armazenamento de grãos em pequenas propriedades de São Francisco, Paraíba, Brasil. Colloquium Agrariae, 14(2), 35-47.

Ruiz, A., Couto, A. \& Aguado, P.J. (2012). Design and instrumentation of a mid-size test station for measuring static and dynamic pressures in silos under different conditions - Part II: Construction and validation. Computers and Electronics in Agriculture, 85, 174-187.

Sadowski, A. J. \& Rotter, J. M. (2011). Steel silos with different aspect ratios: I - behavior under concentric discharge. Journal of Constructional Steel Research, 67(10). 1537-1544.

Saleh, K., Golshan, S. \& Zarghami, R. (2018). A review on gravity flow of free-flowing granular solids in silos - Basics and practical aspects. Chemical Engineering Science, 192, 1011-1035.

Samsu, J., Zhou, X., Pinson, D. \& Sheng Chew. (2018). Flow and wall stress analysis of granular materials around blocks attached to a wall, Powder Technology, 330, 431-444.

Schuricht, T., Furll, C., \& Enstad, G. G. (2009). Experimental and calculated loads oncone in cone installations. Particulate Science and Technology, 27(4), $286-296$.

Silva, L. A. (2019). Efeito de inserts no padrão de fluxo e vazão mássica em silo vertical esbelto para farinha de milho flocada. Dissertação apresentada ao Programa de Pós-graduação em Engenharia Agrícola da Universidade Federal de Campina Grande, como parte das exigências para obtenção do título de Mestre em Engenharia Agrícola.

Silva, Neto. \& Santos, T. L. (2019). O déficit na capacidade estática de armazenamento nas regiões centro-oeste e sul do Brasil. Revista de Economia e Agronegócio, 17(3), 507-530.

Slominski, C., Niedostatkiewicz, M. \& Tejchman, J. (2007). Application of particle image velocimetry (PIV) for deformation measurement during granular silo flow. Powder Technology, 173, 1-18.

Sun, S., Zhao, J. \& Zhang, C. (2018). Calculation of Silo Wall Pressure considering the Intermediate Stress Effect. Advances in Civil Engineering, 2018(1), 110 .

Tascón, A. (2017) Design of silos for dust explosions: Determination of vent area sizes and explosion pressures. Engineering Structures, 134, 1-10.

Teixeira, L. G. dos R. (2006). Determinação das propriedades físicas e de fluxo do café para projeto estrutural de silos e equipamentos. Dissertação (Mestrado em Engenharia Agrícola) -Universidade Federal de Lavras, Lavras.

Wang, Y., Lu, Y. \& Ooi, J. Y. (2015). A numerical study of wall pressure and granular flow in a flat-bottomed silo. Powder Technology, 282, 43-54.

Wójcik, M. \& Tejchman, J. (2008). Application of an uncoupled ALE-formulation to conned granular flow in silos. The 12th International Conference of International Association for Computer Methods and Advances in Geomechanics (IACMAG), Goa, India, X, 1-6.

Wójcik, M., Tejchman, J. \& Enstad, G. G. (2012). Confined granular flow in silos with inserts — Full-scale experiments. Powder Technology, $222(1), 15$ - 36.

Wójcik, M., Sondej, M., Rejowski, K. \& Tejchman, J. (2017). Full-scale experiments on wheat flow in steel silo composed of corrugated walls and columns, Powder Technology, 311, 537-555.

Xue, J., Schiano, S., Zhong, W., Chen, L. \& Wu, C.Y. (2019). Determination of the flow/no-flow transition from a flat bottom hopper. Powder Technology, $358(1)$, p. 55-61.

Yang, S. C. \& Hsiau, S. S. (2001). The simulation and experimental study of granular materials discharged from a silo with the placement of inserts. Powder Technology, 120(3), 244-255.

Yu, Xie., Raeesi, A., Ghaednia, H., Heydariha, J., Das, S. \& Xie, S. (2017). Behavior of a Large Steel Field Silo Structure Subject to Grain Loading. Journal of Performance of Constructed Facilities, 31(5): 04017038. 
Research, Society and Development, v. 10, n. 4, e55710414580, 2021

(CC BY 4.0) | ISSN 2525-3409 | DOI: http://dx.doi.org/10.33448/rsd-v10i4.14580

Zhang, Y., Jia, F., Zeng, Y., Han, Y. \& Xiao. Y. (2018). DEM study in the critical height of flow mechanism transition in a conical silo. Powder Technology, $331,98-106$.

Zuriguel, I., Janda, A., Garcimartín, A., Lozano, C., Arévalo, R. \& Maza, D. (2011). Silo clogging reduction by the presence of an obstacle. Physical Review Letters, 107(27), 278001, 2011. 